University of Massachusetts Amherst

ScholarWorks@UMass Amherst

Communication Graduate Student Publication

Series

Communication

2020

Binge-Watching as a Predictor of Narrative Transportation Using

HLM

Stephen Warren

University of Massachusetts Amherst, smwarren@umass.edu

Follow this and additional works at: https://scholarworks.umass.edu/communication_grads_pubs

Warren, Stephen, "Binge-Watching as a Predictor of Narrative Transportation Using HLM" (2020). Journal of Broadcasting \& Electronic Media. 16.

https://doi.org/10.1080/08838151.2020.1718985

This Article is brought to you for free and open access by the Communication at ScholarWorks@UMass Amherst. It has been accepted for inclusion in Communication Graduate Student Publication Series by an authorized administrator of ScholarWorks@UMass Amherst. For more information, please contact scholarworks@library.umass.edu. 


\begin{abstract}
This study explores the changing state of television by measuring binge-watching and its association with narrative transportation using longitudinal data. Hierarchical Linear Modeling found that amount of binge-watching had a positive logarithmic association with transportation the effect power lessens as binge-watching rate increases. Further, one's typical binge frequency weakened the relationship between viewing session length and transportation. Overall, more frequent binge-watching reduces its effect power on transportation. Implications for theory and industry are also discussed.
\end{abstract}

Keywords: binge-watching, transportation, hlm, television, streaming 


\section{Binge-Watching as a Predictor of Narrative Transportation Using HLM}

It is difficult to talk about television in 2019 without using the term "binge-watching." While the idea of television marathons has been around for decades, as anyone who has sat through hours of Law \& Order would know, binge-watching - generally defined as watching multiple sequential episodes of one show continuously - has become one of society's most popular leisure activities. This paper explores the effects of this activity on audience transportation into the television program being binged. Herein, television refers to traditional audio-visual broadcasting or streaming subscription platforms.

By $2014,44 \%$ of US households at some point had watched three or more episodes of a television show in one day (MarketingCharts Staff, 2014). In 2017, that number was up to $73 \%$ (Westcott, Lippstreu, \& Cutbill, 2017). Not only are people binge-watching, but they are really liking it. Netflix found $73 \%$ of US citizens polled enjoyed and had positive feelings towards the activity (West, 2014). However, others feel it may not be so harmless.

As with other leisure activities, the debate over whether or not binge-watching may be detrimental has surfaced. Matrix (2014) compares the activity to eating junk food: delicious, hard to stop and consequently feeling ill and unsatisfied (Matrix, 2014). Indeed, current research tends to focus on these addictive, harmful qualities associated with other excessive behaviors. Addiction to or dependency upon media stimulation were suggested as possible characteristics of those engaging in the activity, or "binge-watchers" (Devasagayam, 2014; Riddle, Peebles, Davis, $\mathrm{Xu}, \&$ Schroeder, 2017). Further, binge-watchers were found to more likely be depressed or lonely than non-binge-watchers (Sung, Kang, \& Lee, 2015a).

As binge-watching continues to gain popularity, more research on the activity is needed to address two important aspects of the phenomenon often neglected. First, although TV 
episodes can vary considerably in length, binge-watching activity is never defined more specifically than a number of episodes watched consecutively, typically two or three (e.g. Davison, 2013; Riddle et al., 2017). Secondly, the research generally considers binge-watching as different than traditional television viewing. However, except for Riddle et al. (2017), audiences' specific involvement is not studied to determine how viewers interact with binged content, as has been done with traditional fictional television series (Godlewski \& Perse, 2010; Lu \& Lo, 2007; McKenzie, 2000).

Often, binge-watchers report being lost in the story (Petersen, 2016), similar to the effects from a good novel (Perks, 2015). One concept that could address this interaction is one in which media involvement has been studied frequently: narrative transportation, or how absorbed one is in the narrative. Based on these deficiencies in binge-watching research, this study addresses the following research question: to what extent does binge-watching affect the viewer's transportation with the content?

Studying binge-watching and audience transportation is important for several reasons. First, this study adds to the limited research by establishing more specific parameters for universally defining binge-watching. Secondly, this helps to determine if binge-watching needs to be monitored similarly to other bingeing behaviors, as has been suggested (Sung, Kang, \& Lee, 2015b; Wheeler \& Hackney, 2015; etc.). Thirdly, transportation is often linked to increased content-based beliefs (e.g. Dal Cin, Zanna, \& Fong, 2004; Murphy, Frank, Moran, \& PatnoeWoodley, 2011). Understanding the link to transportation levels could catalyze future research on potential persuasive effects of binge-watching. 


\section{Literature Review}

As mentioned previously, binge-watching is gaining popularity and is consistently seen as mostly positive by viewers (e.g. Matrix, 2014; Spangler, 2013). Of those polled, 79\% believe television shows are more enjoyable when binge-watched (West, 2014). Further, one quarter of those who had finished a full season within a month did so within two days (Spangler, 2013). One reason could be that this condensed viewing may be somewhat closer to the act of reading than traditional television viewing (Giuffre, 2013). An aspect of this evolution may be due to the expansion of consumer viewing options.

\section{Increase in Viewer Option}

Binge-watching or marathoning are not necessarily new phenomena. Most broadly, readers of fiction have lost sleep just to finish novels since before TV was invented (Perks, 2015). And, networks have been airing TV marathons since before the cable age (Jenner, 2015). The difference is that binge-watchers choose what to watch on their own schedules, not the network executives'. As such, this increase in choice could be one explanation for the phenomenon. Whether customers are "cutting the cord" (Westcott et al., 2017), streaming content or simply partaking in less appointment viewing (MarketingCharts Staff, 2014), there are increasingly more alternatives to traditional television (Johnson, 2014). For binge-watching, this means more than simply deciding what to watch.

\section{Viewing Aspects}

Binge-watching research needs to look at not just who is watching what, but how, when, and at what rate these individuals are watching. Besides choosing what to watch, the act of binge-watching includes choosing when and how many episodes to watch (Hallinan \& Striphas, 2014). People are more likely to binge-watch when they have free time and access to a show 
(Devasagayam, 2014). Some suggest that this could lead to consumption excess, habituation, or replacing other activities completely (e.g. Davison, 2013; Matrix, 2014). Either way, bingewatching is seen as a way to distract and remove oneself from the outside world (West, 2014).

Another characteristic of the binge-watching process is that viewers also choose when to stop watching. Unlike a television network schedule, only one's own schedule or ability causes restrictions to the activity. Over-the-Top (OTT) services, like Netflix, know this, hence their post-play features that skip the closing credits and subsequent opening credits - something binge-watchers prefer anyway (Davison, 2013). Just as consecutively reading multiple chapters of a novel is ideal for getting the most out of the book, viewers can be more conscious of the season as a singular narrative piece (Newman, 2009; Thompson, 2007). In fact, the concurrent increase in serialized, hybrid-genre television programs with overarching storylines spanning entire seasons, much akin to stories told in literature - often called "quality TV" (Bilandzic, Hastall, \& Sukalla, 2017; McCabe \& Akass, 2007) in the past twenty years speaks to this.

\section{Binge-Watching Research}

Because the phenomenon's popularity is recent, research regarding binge-watching is fairly limited. Consumers have been found to skip openings, especially when they watched episodes "back-to-back in a compressed timeframe" (Davison, 2013), as well as report addictive tendencies, like losing track of time and feeling empty when a series ends (Devasagayam, 2014; Flayelle, Maurage, \& Billieux, 2017; Riddle et al., 2017). However, these results are correlational or from self-reported focus groups, not causal. Others have claimed that bingewatching causes depression or loneliness, but these studies do not have the research design necessary to confirm causal direction (Sung et al., 2015a). 
Binge-watchers achieved some level of escapism during viewing, and did so for relaxation, engagement, and hedonism (Peña, 2015). Further, those planning to binge considered quality of and the chance to have "water cooler" talks about the show (Pittman \& Sheehan, 2015). Further, self-reported binge-watching increases took away from "other goal pursuits" (WaltonPattison, Dombrowski, \& Presseau, 2018). In-depth interviews have added the escapism aspect: a "walk through the wardrobe" - the feeling of being within the narrative world (Perks, 2015). This notion of being fully immersed in the content provides an excellent foundation on which to build research concerning the effects of binge-watching.

As mentioned, current studies often do not operationalize binge-watching beyond the number of episodes viewed (e.g. Devasagayam, 2014; Matrix, 2014; Peña, 2015), despite the call for enhanced measurement of the construct (Flayelle et al., 2017; Walton-Pattison et al., 2018). While episode number is important, viewing time can also vary considerably: two episodes of Robot Chicken totals 30 minutes, while Black Mirror can run at over 2 hours. Other studies are specific on timeframe, but lack the number of consecutive episodes watched (Perks, 2015). This measure is closer to the essence of binge-watching: people can choose to do the viewing whenever they want.

Perks (2015) equates binge-watching to staying up late to finish a large jigsaw puzzle. It was an obsession. Further, people feel a void after a show ends (Devasagayam, 2014; Riddle et al., 2017). In other words, viewers feel longing for the narrative world that they experienced in the TV show. John Gardner said that a good fiction writer can "create a vivid and continuous dream" in the reader's head (Gardner, 1991). Researchers refer to this concept of experiential imagery as transportation. 


\section{Transportation Theory}

The most basic explanation of transportation is that it is the state of being absorbed or enthralled in a narrative world. A person travels to the narrative world and returns somewhat changed by the journey (Gerrig, 1993). Essentially, individuals become so engrossed in a text through a blending of narrative attention, mental imagery and emotional connection - that they are more attentive to the fictional world than the real world, potentially affecting story-consistent belief change and protagonist favorability (Green \& Brock, 2000). Applied to television and film, the mental imagery is replaced with mental rumination, or extensive thinking about the narrative, even after exposure (Riddle, 2013).

Most transportation literature examines two relationships: antecedents and transportation's effect on individuals' narrative-related beliefs. The latter relationship has been quite consistent, finding that transportation and content-specific belief change are positively related (Bilandzic \& Busselle, 2008; Green, 2004; Green \& Brock, 2000; Murphy et al., 2011; etc.). Conversely, possible factors that influence the level of transportation include genre (McKinley, 2013), quality of the work (Dal Cin et al., 2004), narrative-related experience (Green, 2004) and viewing time (McKinley, 2013). What is common is the notion that individuals escape to the fictional world and have limited contact or attention to the real world, a concept similar to the escapism that viewers can experience during binge-watching (Perks, 2015).

\section{Hypothesis/Research Questions}

Viewers' engagement with visual media, including narrative understanding, focus and emotional connection, are correlated with transportation levels (Busselle \& Bilandzic, 2009). Relatedly, binge-watching allows for viewers to identify more subtle aspects of the narrative (Graves, 2015; Thompson, 2007) and perceive whole seasons as singular narrative pieces 
(Newman, 2009). Therefore, binge-watching may also be contributing to viewer engagement, affecting transportation. In addition, prior narrative familiarity (Green, 2004) and premonition of forthcoming storylines (Tal-Or \& Cohen, 2010) affect transportation. This would suggest that watching sequential episodes of one show would lead to higher transportation, because the viewer understands that the narrative and characters will continue where the just-watched episode ended. Likewise, two other variables positively related to transportation - extended viewing time (McKinley, 2013) and perceived advertisement intrusiveness (Wang \& Calder, 2006) - are both associated with binge-watching (typically with ads being limited during the activity) (Perks, 2015; Sung et al., 2015a). Based on these observations, the first hypothesis is as follows:

H1: As time spent binge-watching a series increases, the level of viewers' transportation with said series will increase.

Some have previously suggested that transportation could be reciprocating, in which certain narratives lead to transportation, which in turn lead to the desire for similar narratives, with mixed results (Bilandzic \& Busselle, 2008). Relatedly, binge-watching changes how the narrative is consumed, so one's regularity of the activity could affect transportation levels. Does one's predisposition to frequent binge-watching facilitate transportation, similarly to the concept of transportability (Dal Cin et al., 2004)? Conversely, infrequency could make each bout of binge-watching more impactful, leading to greater transportation. As such, two research questions were asked to explore how viewers' prior viewing habits and knowledge affected transportation:

RQ1: To what extent does a viewer's familiarity with various series impact his or her transportation with a related similarly "quality TV" series? 
RQ2: To what extent does a viewer's general binge-watching frequency impact his or her transportation with a binge-watched series?

\section{Method}

In order to measure how transportation was affected by binge-watching rate, a 4-wave panel study was employed. Participants were instructed to watch one television show of their choice from the list and fill out weekly subsequent surveys regarding this viewing time for three weeks. Transportation studies typically utilize experimental design (i.e. Busselle \& Bilandzic, 2009; Green \& Brock, 2000; Riddle, 2013). However, one goal of this study was to increase external validity through a more natural consumption experience. A panel survey design helps achieve this (Vogt \& Johnson, 2011). Previously, this method has been utilized in other bingewatching research focusing on causation (Peña, 2015).

\section{Participants}

Respondents were recruited through both MTurk and classes from a northeastern university. Quality precautions were taken to filter out "bots" and/or bad responses in MTurk, including checking location data and open-ended responses (Mason \& Suri, 2012). Those not meeting the exclusion criteria were not invited to further participate. All participants were incentivized by two $\$ 200$ gift card drawings in which only those whom completed all necessary questionnaires were entered into the drawing. After MTurk filtering $(n=467)$, a total of 376 individuals completed the week 1 questionnaire, and 262 completed diary entries (week $2: n=$ 262; week 3: $n=227$; week 4: $n=200$ ). Only those who completed at least one diary and the pre-questionnaire were included. Of the 216 who met these criteria, $73.76 \%$ were white $(8.1 \%$ Asian; 5.0\% African-American; 7.2\% Hispanic/Latino), 40.09\% were male, and the average age was $27.61(S D=9.77 ; 18-60)$. 


\section{Instrumentation}

A week 1/baseline questionnaire consistent with other media exposure studies was employed to find viewer program familiarity and overall binge frequency (e.i. Bilandzic \& Busselle, 2008; Murphy et al., 2011). Participants were asked how frequently they typically binge-watched, ranging from 0 ("Never") to 6 ("Once a Day") $(M=3.82, S D=1.96)$ (Sung et al., 2015a). However, binge-watching was not defined as "two to three episodes in a row." Instead, participants reported binge-watching frequency with regard to their personal definition of the concept. While this potentially limits reliability, peoples' perceptions of how often they bingewatch is reliant upon their average TV consumption (Wagner, 2016). The purpose of this measurement design was to improve the naturalism and account for various lifestyles and viewing patterns.

Professionally produced texts have been found to be more transporting than researchercreated content (Green \& Brock, 2000). As such, participants chose between ten shows available on Netflix, the most popular streaming site, to view for the duration of the study. The shows came from an aggregation of seven Internet lists of top shows to binge-watch (see Appendix A). These shows are approximately one hour long and serialized, i.e. the episodes must be viewed sequentially for full understanding of the storylines. Limiting to one-hour fictional programs was an attempt to limit internal invalidity and variance in transportation levels due to differing programs or viewing time. Before selecting a show, participants were asked how familiar they were with each show listed Peña (2015), from 0 "Never Heard of It" to 6 "Seen Every Episode" $(M=2.98, S D=0.63)$. These shows blend genres, deal with moral issues, and have cinematic aesthetics, and therefore all include characteristics of programs broadly considered "quality TV" (McCabe \& Akass, 2007). As such, this program familiarity variable was used to measure if 
respondents" familiarity with this set of "quality TV" series impacted transportation (RQ1). Both binge frequency and program familiarity were mean-centered, so 0 represents a person with typical familiarity with the shows and average binge-watching frequency.

Participants then selected one of the ten shows, that they were less familiar with, to watch for all three weeks. Previous researchers have edited or created content to control media exposure (McKinley, 2013; Murphy et al., 2011; Riddle, 2013; etc.). However, transportation may be negatively affected if individuals are not given their choice in consumption (Green \& Brock, 2000; Moyer-Gusé \& Nabi, 2010). Allowing the participants more choice in what to watch - reflecting a unique aspect of binge-watching - naturalizes the study and increases external validity.

Participants accessed the show through Netflix on their own and watched episodes at their own pace, increasing ecological validity. They were informed that their viewing was being tracked for the study and asked to take mental note of how much they watched. Every Sunday night, participants received a link to the questionnaire regarding the episodes viewed during that prior week.

Weekly Binge-Watching. After each week, participants were asked to reflect on the past seven days and record their daily viewing activity in a survey diary broken down by day and hour. This repeated for three weeks. The two independent variables associated with this bingewatching rate were two time-varying covariates. The first binge variable was the total number of viewing sessions an individual reported. A session was any instance in which a person reported at least one hour of viewing time (i.e. the person watched at least one episode during one sitting). Sessions were not dependent upon length of time (one session could refer to one hour or twelve, 
for example). The second binge variable was the average number of hours watched per session to further account for length of time spent viewing. Both variables were measured weekly.

Transportation. To measure the dependent variable, a modified nine-item version of the Green and Brock (2000) general transportation scale was administered weekly. Riddle's (2013) modifications - originally used to determine the impact of vividness of media content on subcomponents of transportation - guided the adapting of the original scale to this study's focus on visual media (Riddle, 2013). For example, items tapping mental imagery as a result of reading were modified to be more appropriate for television content. Further, the item "I wanted to learn how the narrative ended" (Green \& Brock, 2000) was reworded to measure one's intent to watch more episodes in the coming week. The items were on a five-point Likert scale, ranging from 1 (“strongly disagree") to 5 ("strongly agree”). Examples include "I found my mind wandering while watching the show" (reverse-coded) and "The TV show affected me emotionally" (Riddle, 2013). The scale was reliable, with an overall Cronbach's alpha of .78 (week 1, $\alpha=.70$; week 2, $\alpha=.81$; week 3, $\alpha=.83$ ).

If a participant finished the show prior to the completion of the three-week timeframe, he or she was asked to select another show from the list to watch for the remainder of the study and complete the remaining weekly questionnaires with regard to this new show $(n=10)$.

Both questionnaires were pre-tested with approximately ten percent of the intended sample size, and any comments or issues were addressed and revised before final recruitment.

\section{Hierarchical Linear Modeling}

To analyze the longitudinal data, a two-level hierarchical linear model was developed using HLM 7.0 (Raudenbush, Bryk, Cheong, \& Congdon, 2004). HLM allows for Level-1 to represent the observed measures of each respondent at each time, nested within Level-2 (the 
individual level) and look at individuals' variance in the Level-1 variables, even if some individuals' data are missing at particular timepoints (Chapman, Hesketh, \& Kistler, 2002). In this study, Level-1 contains the weekly binge-watching and transportation measures, and Level-2 houses each individual's binge frequency and show familiarity, resulting in the final model, as outlined in the results.

\section{Results}

Lost, Breaking Bad and American Horror Story $(n=14)$ were chosen the least. Mad Men $(n=37)$ was the most selected show. Weekly transportation averages ranged from 1.62 (The Walking Dead; $S D=.45$ ) to 1.86 (Buffy the Vampire Slayer; $S D=.52$ ), with an overall mean of $1.74(S D=.47)$. Both viewing variables - total sessions $(M=2.86, S D=3.61)$ and hours per session $(M=1.37, S D=1.27)$ - were non-normally distributed (skewness $=2.42$, kurtosis $=$ 8.62 ; and skewness $=1.38$, kurtosis $=2.78$, respectively). Thus, both were log-transformed to help normalize the distributions for analysis.

A Pearson's correlation test was conducted between the predictor and outcome variables at level-1. Transportation was weakly correlated with both viewing sessions $(r=.24, p \leq .001)$ and hours per session $(r=.12, p \leq .001)$. Likewise, total episodes and hours per viewing session had a moderate correlation $(r=.39, p \leq .001)$. ANOVAS for each week showed no significant differences for total sessions, hours per session or transportation due to program viewed.

\section{Hierarchical Linear Modeling}

Three models were estimated using HLM 7.0. An unconditional growth model with only week 2 at level-1 was first tested to help identify if there was change in transportation over time (repeated measures). Week was centered around week 1, because this was the first week of DV/IV data collection, as well as the week with most data points $(n=262)$. Further, this data 
point represents a "baseline" measured when respondents had the least interaction with their show.

The results of model 1 (linear growth) are shown in Table 1. Respondents had an average transportation level in week 2 of $1.77\left(\beta_{00}=1.77, S E=.03, p \leq .001\right)$. The confidence interval was $\mathrm{CI}=(1.71,1.83)$. There was no significant weekly change in transportation $\left(\beta_{10}=-0.04, S E\right.$ $=.02, p=.052)$. The variances for both the intercept $\left(\sigma_{0}^{2}=.13, p \leq .001\right)$ and the slope $\left(\sigma_{1}^{2}\right.$ $=.02, p \leq .001)$ were statistically significant. Therefore, individuals varied significantly in their baseline transportation level, as well as the change in transportation level weekly, implying no trend related to time.

\section{Hypothesis 1}

Hypothesis 1 predicted that as binge-watching increased, a viewer's transportation level would increase. To test H1, Model 2 included the two binge-watching variables at level-1: sessions and hours per session. This inclusion produced a significant reduction in model deviance $\left(x^{2}(4)=41.77, p \leq .001\right)$, indicating improved model fit (see Table 1$)$.

In Model 2, respondents with no viewing sessions or hours had an average transportation level in week 1 of $1.46\left(\beta_{00}=1.46, S E=.07, p \leq .001, \mathrm{CI}=(1.33,1.59)\right)$. Time was still nonsignificant. In this model, increased total sessions was associated with greater transportation $\left(\beta_{20}\right.$ $=0.14, S E=.03, p \leq .001)$, controlling for time. The log-function of average hours per session was approaching significance in this regard $\left(\beta_{30}=0.10, S E=.05, p=.062\right)$.

Total error variance of the sample was $\sigma^{2}=0.08$, and the intercept-slope covariance was 0.01. The variances for both the intercept $\left(\sigma_{0}^{2}=.12, p \leq .001\right)$ and the slope $\left(\sigma_{1}^{2}=.01, p \leq .001\right)$ were statistically significant. Therefore, individuals still varied significantly in their baseline 
transportation level, as well as the change in transportation level when accounting for their binge-watching rate, implying no trend related to time.

Figure 1 shows a linear curve of transportation based on total sessions and length per session (transformed back from natural logs). An increase in total viewing sessions predicts an increase in transportation, but that effect size weakens as one partakes in more viewing sessions. An increase in the average length per session increases transportation further. Overall, Hypothesis 1 was supported.

(Insert Figure 1 Here)

\section{Research Questions}

Research Questions 1 and 2 explored the effect of a viewer's program familiarity and general binge-watching frequency on his or her transportation level, respectively. To test these, show familiarity and binge frequency variables were added at level-2. To determine the fixed and random effects of the final model, model comparison tests were employed using various combinations. The best fit (lowest deviance with significant model comparison test) was used,

as outlined below as Model 3. The final conditional model increased model fit significantly $\left(x^{2}{ }_{(6)}\right.$ $=18.30, p \leq .01)$. See Table 1 for complete modeling results. The resulting model was:

$$
\begin{aligned}
& \text { TRANSPORT }=\pi_{0}+\pi_{1}(\text { WEEK } 1)+\pi_{2}(\text { SESSIONS })+\pi_{3}(\text { SESSION MEAN })+e, \\
& \pi_{0}=\beta_{00}+\beta_{01}(\text { FAMILIARITY })+\beta_{02}(\text { FREQUENCY })+r, \\
& \pi_{1}=\beta_{10}+\beta_{11}(\text { FAMILIARITY })+\beta_{12}(\text { FREQUENCY })+r, \\
& \pi_{2}=\beta_{20} \\
& \pi_{3}=\beta_{30}+\beta_{31}(\text { FAMILIARITY })+\beta_{32}(\text { FREQUENCY }) \\
& (\text { Insert Table 1 Here })
\end{aligned}
$$


In Model 3, respondents had a base transportation level in week 1 of $1.46\left(\beta_{00}=1.47, S E\right.$ $=.07, p \leq .001, \mathrm{CI}=[1.33,1.61])$. At level 2 , both program familiarity $\left(\beta_{01}=0.18, S E=.09, p\right.$ $\leq .05)$ and binge frequency $\left(\beta_{02}=0.09, S E=.03, p \leq .01\right)$ had significant effects for intercept in the model. This means that holding all else constant, an increase in familiarity with the shows (RQ1) predicted an increase of 0.18 in baseline transportation. Likewise, an increase in overall binge frequency (RQ2) predicted an increase of 0.09 in baseline transportation. In sum, as show familiarity and general binge frequency increase, initial transportation levels increased.

Time remained non-significant $\left(\beta_{10}=-0.02, S E=.02, p=.286\right)$. Neither program familiarity $\left(\beta_{11}=-0.01, S E=.03, p=.713\right)$ nor binge frequency $\left(\beta_{12}=-0.01, S E=.01, p=.946\right)$ were significant at level-2, indicating the variables had no impact on growth due to time.

Consistent with Model 2, the log-function of total sessions was significant $\left(\beta_{20}=0.14, S E\right.$ $=.03, p \leq .001)$, and the log-function of average hours per session approached significance $\left(\beta_{30}=\right.$ 0.103, $S E=.05, p=.062$ ). At level-2, show familiarity was not significant on average session length slope $\left(\beta_{31}=-.12, S E=.07, p=.108\right)$. This suggests that familiarity with the shows did not change how session length affected transportation. On the other hand, binge frequency was marginally significant $\left(\beta_{32}=-0.046, S E=.03, p=.08\right)$ and had a negative coefficient. This indicates that, when holding all else constant, a one unit increase in typical binge-watching behavior predicted a .046 decrease in the effect size of session length on transportation. This relationship is displayed visually in Figure 2. Among those who generally binge-watch more frequently (RQ2), average viewing session length impacts transportation less than it does for those who binge-watch less frequently. So, someone who binge-watches once monthly will be much more transported the longer he or she watches each session, while a weekly bingewatcher's transportation will begin to plateau. 
Total error variance was $\sigma^{2}=0.081$. Variances for intercept $\left(\sigma 0^{2}=.11, p \leq .001\right)$ and slope $\left(\sigma_{1}^{2}=.01, p \leq .001\right)$ were statistically significant. Individuals still varied significantly in their baseline and change in transportation level from binge-watching. So, other factors were still at play.

(Figure 2 Here)

Because respondents were able to watch different programs, a series of fourth models were fit to see whether program viewed affected the results. Dummy variables were created for each value of the program variable. So, if Person A watched Breaking Bad, Person A would have a value of 1 for the Breaking Bad dummy variable and a 0 for all other dummy variables. Then, ten models, each with a different reference category, were tested to compare the reference program against all each other program, similarly to the process for testing dummy variables in multiple regression. First, for instance, nine dummy variables were included in a model, with the American Horror Story variable excluded to be the reference category, to test the viewing of American Horror Story against each of the other programs. The basic level-1 regression equation for that model would be:

$$
\begin{aligned}
& \text { TRANSPORT }=\pi_{0}+\pi_{1}(\text { WEEK1 })+\pi_{2}(\operatorname{SESSIONS})+\pi_{3}(\operatorname{SESSION~MEAN})+\pi_{4}(B B)+\pi 5(B U F F) \\
& +\pi_{6}(D E X)+\pi_{7}(H O C)+\pi_{8}(L O S T)+\pi_{9}(M A D)+\pi_{10}(O R A N G E)+\pi_{11}(S U P)+\pi_{12}(W A L K)+e
\end{aligned}
$$

If any $p$-values for the resulting $\pi$ coefficients for any dummy variables in the model are significant, that indicates a significant difference between the viewing program in the reference group and another program in the list. Next, Breaking Bad was used as a reference (i.e. excluded with all other program dummies included) to test against each of the other nine programs. This process was repeated until the potential role of each possible program was compared against each of the other programs. These tests were first performed with the program variables at level- 
2 , between persons. The resulting models were not significantly better fits than the current models 3 or 2 and found no differences in the $p$-values of the significant beta coefficients nor changes to the size of the coefficients beyond three one-thousandths of a unit. Only one significant difference between all program variable comparisons in the ten models was found: those that watched Supernatural had significantly lower baseline starting transportation than those watching Mad Men. However as mentioned, this was in a model that had worse fit and minimal differences from model 3. Lastly, to account for the fact that some respondents $(n=$ 10) switched programs before the close of the study, ten additional models were fit with the program dummy variables at level-1 (within persons), repeating the same program reference category process as stated above. In this case, the dummy variables measured each respondent's program choice for each week. Thus, if Person A switched to Mad Men for weeks 2 and 3, Person A's Breaking Bad dummy variable values would sequentially be 1, 0, 0, and Mad Men would be $0,1,1$. As with the other program dummy models, these models were not significantly better fits, yielded minimal differences from model 3, and resulted in the same sole significant difference between shows as at level-2. As a result of these analyses, model 3 above was deemed the best model for analysis and interpretation. On balance, the patterns found for transportation were not significantly different based on the program selected by participants.

\section{Discussion}

This study sought to find the effects of binge-watching on viewers' transportation levels using a more detailed measurement than has previously been used. One contribution of this study was the successful application of a diary-based self-report measurement of viewing time. Diaries can help with accuracy of exposure measures, while maintaining some level of naturalization (Fikkers, Piotrowski, \& Valkenburg, 2017), something paramount to the binge- 
watching process. The diary system was also available on mobile devices, which can allow users' typical routines to remain despite participating in a study (Link et al., 2014; Ohme, Albaek, \& H. de Vreese, 2016). Being able to increase the naturalization of consumption, while maintaining some internal validity, shows that diaries can be a feasible measurement for transportation research and usual belief change and persuasion variables therein.

Hypothesis 1 was supported. The more times a person watched, as well as the longer each viewing session was, the greater the level of transportation. Just as narrative and genrerelated experience increases transportation (Green, 2004), watching a serialized show in chronological order provides greater knowledge about characters' backgrounds and tendencies, as well as the fictional world. So, when a character is killed off on The Walking Dead, a frequent viewer will know the full impact it will have versus someone with more limited knowledge of the overarching storylines. For persuasion, this means that a viewer may be more susceptible to beliefs within the narrative world the more he or she consumes said media, especially if the specific narrative is continuous and serialized. Given the persistent relationship between transportation and story-consistent beliefs (van Laer, de Ruyter, Visconti, \& Wetzels, 2014), future research should consider how increased, sequential viewing affects belief change and how serialized stories influence this.

However, this binge-watching/transportation relationship weakens as an individual partakes in more viewing sessions. This suggests that while people are immersed deeper into a story the more they watch, some desensitization may occur, similar to violent media exposure (Carnagey, Anderson, \& Bushman, 2007). The question remains if this weakening occurs due to increased exposure to the particular show or from increased viewing itself. Considering transportability - one's likelihood of being transported (Bilandzic \& Busselle, 2008) - if overall 
viewing is the reason, each subsequent viewing session could eventually result in a plateau effect. If there is indeed some limit to transportation from more sessions, this habituation could also affect one's susceptibility to persuasion or belief change. Further, how do screen size or location affect these processes? These are questions for future studies.

For the research questions, the more familiar with the shows (RQ1) and the frequency with which one binge-watches (RQ2) increased baseline transportation after the first week of viewing. Show familiarity did not impact the relationship between session length and transportation, however. This could speak to varying themes and tones, despite the shows exhibiting serialized, complex storylines and genre-blending content. Though program watched did not improve model fit significantly, dismissing program impact entirely would be unwise. Future research should account for and include specific genres and varied themes and complexity to determine their impact on transportation. Researchers should also consider non-fiction series that are often among the top series binged, like the highly popular Making a Murderer (Donegan, 2018). It is a limitation herein that all these shows were considered "quality TV" (McCabe \& Akass, 2007), which in and of themselves could have contributed to transportation. Thus, researchers should implement content analyses of both high- versus low-transporting texts and frequently versus infrequently binged programs to understand how/if viewing behaviors and content relate.

The more often a person typically binge-watches (RQ2), the weaker the relationship between transportation and session length. Those more accustomed to binge-watching were less affected by longer binge sessions, suggesting a desensitization effect. Additionally, the ability of a binge session to help achieve the "escape" gratification (Pittman \& Sheehan, 2015) could become minimal if used too frequently. Plus, it is possible that this plateaued strength of effect 
could transfer to persuasion or enjoyment. Another consideration is unrelated to effects - it is possible that the shows uniformly decreased in quality. To test this, a content analysis with some criteria of quality would be needed.

\section{Implications and Limitations}

This paper shows that binge-watching can be measured as an independent variable, with outcome variables measured as a result of binge-watching. Admittedly, one concern could be the claim of causality herein. Typically, transportation studies use experimental design (van Laer et al., 2014), helping explain time-order while limiting participant exposure to the stimuli. However, examining how different rates of viewing affect the transportation and belief change process facilitates understanding these effects in the real world. Because of the time-order of this panel design, as well as the lack of growth of transportation over time in the analysis, one could infer some level of causality. Using diaries and panels in this way could be replicated for testing other viewing effects, as well as transportation more naturally.

Another area deserving attention is the proposed distinction between intentional versus unintentional binges (looking at TV addiction) (Riddle et al., 2017). The assumption in this study is that all viewing was intentional, with participants actively measuring their exposure. "Passive learning" still results in information retention (Elenbaas, Boomgaarden, Schuck, \& De Vreese, 2013). It would be interesting to see how susceptibility to persuasion through transportation is affected by whether or not one intentionally binge-watches. Transportation stayed relatively even between shows. Was show a nonfactor, because people chose something to watch that they expected to enjoy? Or, did the shows not affect transportation simply because people were allowed to choose, regardless of if they like it or not? In other words, does freedom 
of choice factor into potential transportation? Looking at intentional and unintentional use would address this.

Transportation research could also look at the difference between content with and without ads (i.e. traditional TV versus OTT/streaming). Transportation has been found to affect perception of ad intrusiveness (Wang \& Calder, 2006). Consider attentional inertia (Hawkins et al., 2002) and the possibility that a viewing session would be fully interrupted by ads. Following the results of this study, a new viewing session then begins when the program continues, thus weakening the effect power between viewing and transportation.

As with any survey method, self-reporting can be a limitation, due to respondent recall inaccuracy and/or bias issues. Much time was spent addressing the balance between construct validity and the naturalistic viewing experience of binge-watching. The panel method used helps with self-report reliability (Scharkow \& Bachl, 2017). Further, the number of episodes watched was nearly identical to the total hours from the diary entries, suggesting consistent self-reporting and sufficient convergent validity. Of note, participants were required to have access to Netflix to participate, potentially limiting generalizability to certain populations. Future studies could employ this same naturalized operationalization with subscribers and non-subscribers to examine if viewing benefits or detriments vary between those groups. Likewise, this method could also be used in experimental design, utilizing a control group in the panel, as a way to increase ecological validity. This would inform subsequent transportation studies observing belief change and persuasion.

\section{Conclusion}

"Television" is a very different word than it used to be. Granted, the spirit of watching a program on a screen still exists. But while some still think of television as the object in the 
living room they gather around each night, newer technology has made television a potentially agnostic medium sometimes requiring only a cell phone and often occurring at a condensed rate. People even prefer this over other viewing behaviors (Nguyen, 2017). How these changes affect audiences is an important question in today's media environment, relating to entertainment and persuasion alike.

This study helps show how scholars can produce sound, valid studies about bingewatching, as they continue to explore how the changing definition of television impacts viewing behaviors. Likewise, this study offers a naturalistic exposure measurement for studying transportation and persuasion. Consumers will continue to watch episodes of shows consecutively. Content creators will continue to develop programming with consecutive viewing in mind. Researchers need to continue to measure and analyze the effects of binge-watching and its related viewing patterns, because it appears the activity will not be cancelled anytime soon. 


\section{References}

Bilandzic, H., \& Busselle, R. W. (2008). Transportation and transportability in the cultivation of genre-consistent attitudes and estimates. Journal of Communication, 58(3), 508-529. doi: 10.1111/j.1460-2466.2008.00397.x

Bilandzic, Hastall, \& Sukalla, 2017. The morality of television genres. Journal of Media Ethics: Exploring Questions of Media Morality, 32(2), 99-117. doi: $10.1080 / 23736992.2017 .1294488$

Bricker, T. (2015). 23 shows you need to binge-watch right now. Retrieved from http://www.eonline.com/photos/12775/23-shows-you-need-to-binge-watch-rightnow/472374

Busselle, R. W., \& Bilandzic, H. (2009). Measuring narrative engagement. Media Psychology, 12(4), 321-347. doi: 10.1080/15213260903287259

Carnagey, N. L., Anderson, C. A., \& Bushman, B. J. (2007). The effect of video game violence on physiological desensitization to real-life violence. Journal of Experimental Social Psychology, 43(3), 489-496. doi: 10.1016/j.jesp.2006.05.003

Chapman, R. S., Hesketh, L. J., \& Kistler, D. J. (2002). Predicting longitudinal change in language production and comprehension in individuals with down syndrome. Journal of Speech Language and Hearing Research, 45(5), 902-915. doi: 10.1044/10924388(2002/073)

Dal Cin, S., Zanna, M. P., \& Fong, G. T. (2004). Narrative persuasion and overcoming resistance. In E. S. Knowles \& J. A. Linn (Eds.), Resistance and Persuasion (pp. 175-191). Mahwah, NJ: Lawrence Erlbaum Associates, Inc.

Davison, A. (2013). The show starts here: Viewers' interactions with recent television serials' 
main title sequences. Sound Effects, 3(1-2), 6-22. Retrieved from http://www.soundeffects.dk/article/view/15633/13507

Devasagayam, R. (2014). Media bingeing: A qualitative study of psychological influences. (D. DeLong, D. Edmiston, \& R. Hightower Jr., Eds.), Marketing Management Association. Chicago, Il.

Donegan, R. (2018). 2018 on Netflix. Netflix. Retrieved from https://media.netflix.com/en/pressreleases/2018-on-netflix-to-all-the-shows-and-movies-weve-loved-before

Elenbaas, M., Boomgaarden, H. G., Schuck, A., \& De Vreese, C. H. (2013). The impact of media coverage and motivation on performance-relevant information. Political Communication, 30(1), 1-16. doi: 10.1080/10584609.2012.737411

Fikkers, K. M., Piotrowski, J. T., \& Valkenburg, P. M. (2017). Assessing the reliability and validity of television and game violence exposure measures. Communication Research, 44(1), 117-143. doi: 10.1177/0093650215573863

Flayelle, M., Maurage, P., \& Billieux, J. (2017). Toward a qualitative understanding of bingewatching behaviors: A focus group approach. Journal of Behavioral Addictions, 6(4), 1-15. doi: 10.1556/2006.6.2017.060

Gardner, J. (1991). The art of fiction: Notes on craft for young writers. New York, NY: Vintage. Gerrig, R. (1993). Experiencing narrative worlds: On the psychological activities of reading. New Haven, CT: Yale University Press.

Giuffre, L. I. Z. (2013). The development of binge watching. Metro, (178), 101-102. Retrieved from http://libezproxy.syr.edu/login?url=http://search.ebscohost.com/login.aspx $?$ direct $=$ true $\& d b=$ cms\&AN=91940213\&site $=$ ehost-live 
Godlewski, L. R., \& Perse, E. M. (2010). Audience activity and reality television: Identification, online activity, and satisfaction. Communication Quarterly, 58(2), 148-169. doi: $10.1080 / 01463371003773358$

Graves, M. (2015). “Chalk one up for the internet: It has killed Arrested Development”. In K. M. Barton (Ed.), A state of Arrested Development: Critical essays on the innovative television comedy (pp. 224-236). Jefferson, NC: McFarland \& Company, Inc.

Green, M. C. (2004). Transportation into narrative worlds: The role of prior knowledge and perceived realism. Discourse Processes, 38(2), 247-266. doi: 10.1207/s15326950dp3802_5

Green, M. C., \& Brock, T. C. (2000). The role of transportation in the persuasiveness of public narratives. Journal of Personality and Social Psychology, 79(5), 701-721. doi: $10.1037 / / 0022-3514.79 .5 .701$

Hallinan, B., \& Striphas, T. (2014). Recommended for you: The Netflix Prize and the production of algorithmic culture. New Media \& Society. doi: 10.1177/1461444814538646

Hawkins, R. P., Pingree, S., Hitchon, J., Gilligan, E., Kahlor, L., Gorham, B., ...Serlin, R. (2002). What holds attention to television? Strategic inertia of looks at content boundaries. Communication Research, 29(1), 3-30. doi: 10.1177/0093650202029001001

Jenner, M. (2015). Binge-watching: Video-on-demand, quality TV and mainstreaming fandom. International Journal of Cultural Studies, 1-17. doi: 10.1177/1367877915606485

Johnson, C. M. (2014). Cutting the cord: Leveling the playing field for virtual cable companies. Law School Student Scholarship, Paper 497.

Lawler, K. (2015). 5 shows to binge-watch this Labor Day. Retrieved from http://entertainthis.usatoday.com/2015/09/07/5-shows-to-binge-watch-this-labor-day/ Link, M. W., Murphy, J., Schober, M., Buskirk, T., Hunter Childs, J., \& Langer Tesfaye, C. 
(2014). Mobile technologies for conducting, augmenting and potentially replacing surveys. Public Opinion Quarterly, 78(4), 779-787. doi: 10.1093/poq/nfu054

Lu, X., \& Lo, H.-P. (2007). Television audience satisfaction: Antecedents and consequences. Journal of Advertising Research, 47(3), 354-363. doi: 10.2501/S0021849907070365

MarketingCharts Staff. (2014). Primary binge-viewing sources, among US households. Retrieved from http://www.marketingcharts.com/television/primary-binge-viewing-sourcesamong-us-households-44385/

Mason, W., \& Suri, S. (2012). Conducting behavioral research on Amazon's Mechanical Turk. Behavioral Research Methods, 44(1), 1-23. doi: 10.3758/s13428-011-0124-6

Matrix, S. (2014). The Netflix effect: Teens, binge watching, and on-demand digital media trends. Jeunesse: Young People, Texts, Cultures, 6(1), 119-138. doi: 10.1353/jeu.2014.0002

McCabe, J., \& Akass, K. (2007). Quality TV: Contemporary American television and beyond. New York, NY: I. B. Tauris.

McKenzie, R. (2000). Audience involvement in the epideictic discourse of television talk shows. Communication Quarterly, 48(2), 190-203. doi: 10.1080/01463370009385590

McKinley, C. J. (2013). Reexamining the link between cultivation factors and viewer involvement: Investigating viewing amount as a catalyst for the transportation process. Communication Studies, 64(1), 66-85. doi: 10.1080/10510974.2012.731466

Moyer-Gusé, E., \& Nabi, R. (2010). Explaining the effects of narrative in an entertainment television program. Human Communication Research, 36, 26-52. doi: 10.1111/j.14682958.2009.01367.x

Murphy, S. T., Frank, L., Moran, M., \& Patnoe-Woodley, P. (2011). Involved, transported, or emotional? Exploring the determinants of change in knowledge, attitudes, and behavior in 
entertainment-education. Journal of Communication, 61, 407-431. doi: 10.1111/j.14602466.2011.01554.x

Newman, M. Z. (2009). TV binge. FlowTV.org. Retrieved from http://flowtv.org

Nguyen, H. (2017). 68\% of millennials prefer full-season TV show releases. YouGov. Retrieved from https://www.statista.com/chart/11423/preferred-way-of-consuming-tv-shows/

Ohme, J., Albaek, E., \& de Vreese, C. (2016). Exposure research going mobile: A smartphonebased measurement of media exposure to political information in a convergent media environment. Communication Methods and Measures, 10(2-3), 135-148. doi:

$10.1080 / 19312458.2016 .1150972$

Peña, L. (2015). Breaking binge: Exploring the effects of binge watching on television viewer reception. S.I. Newhouse School of Public Communications. Syracuse University.

Perks, L. G. (2015). Media marathoning: Immersions in morality. Lanham, Maryland: Lexington Books.

Petersen, T. G. (2016). To binge or not to binge: A qualitative analysis of college students' binge watching habits. The Florida Communication Journal, 44(1), 77-88.

Pittman, M., \& Sheehan, K. (2015). Uses and gratifications of binge-watching television through Netflix. First Monday, 20(10). doi: 10.5210/fm.v20i10.6138

Pritchard, T. (2015). 33 of the best TV shows to binge-watch. Retrieved from http://www.buzzfeed.com/tahliapritchard/brb-watching-tv-forever\#.kuqRGP30o

Ranker TV. (2015). The best shows to binge watch. Retrieved from http://www.ranker.com/list/best-tv-shows-to-binge-watch/ranker-tv

Raudenbush, S. W., Bryk, A., Cheong, Y., \& Congdon, R. (2004). Hierarchical linear and nonlinear modeling. Lincolnwood, IL: Scientific Software International, Inc. 
Riddle, K. (2013). Transportation into vivid media violence: A focus on attention, emotions, and mental rumination. Communication Quarterly, 61(4), 446-462. doi: $10.1080 / 01463373.2013 .799512$

Riddle, K., Peebles, A., Davis, C., Xu, F., \& Schroeder, E. (2017). The addictive potential of television binge watching: Comparing intentional and unintentional binges. Psychology of Popular Media Culture. doi: 10.1037/ppm0000167

Rotten Tomatoes. (2015). 10 TV shows you should binge-watch. Retrieved from http://editorial.rottentomatoes.com/article/10-tv-shows-you-should-binge-watch-thisseptember/

Scharkow, M., \& Bachl, M. (2017). How measurement error in content analysis and self-reported media use leads to minimal media effect findings in linkage analyses. Political Communication, 34(3), 323-343. doi: 10.1080/10584609.2016.1235640

Skells, C. (2015). 10 addicting TV shows that you have to binge-watch. Retrieved from http://screenrant.com/addicting-shows-binge-watch/?view=all

Smith, T. L. (2015). 15 shows to binge watch. Retrieved from http://www.cleveland.com/entertainment/index.ssf/2015/02/15_best_tv_shows_to_bingewatc.html\#0

Spangler, T. (2013). Netflix survey: Binge-watching is not weird or unusual. Retrieved from http://variety.com/2013/digital/news/netflix-survey-binge-watching-is-not-weird-orunusual-1200952292/

Sung, Y. H., Kang, E., \& Lee, W.-N. (2015a). A bad habit for your health? An exploration of psychological factors for binge watching behavior. ICA Annual Conference. San Juan, PR.

Sung, Y. H., Kang, E. Y., \& Lee, W.-N. (2015b). "My name is... and I'm a binge viewer": An 
exploratory study of motivations for binge watching behavior. In American Academy of Advertising. Chicago, Il.

Tal-Or, N., \& Cohen, J. (2010). Understanding audience involvement: Conceptualizing and manipulating identification and transportation. Poetics, 38(4), 402-418. doi: 10.1016/j.poetic.2010.05.004

Thompson, R. (2007). Preface. In J. McCabe \& K. Akass (Eds.), Quality TV: Contemporary American television and beyond. New York, NY: I. B. Tauris.

van Laer, T., de Ruyter, K., Visconti, L., \& Wetzels, M. (2014). The extended transportationimagery model. Journal of Consumer Research, 40(5), 797-817. doi: 10.1086/673383

Vogt, W., \& Johnson, R. (2011). Dictionary of statistics and methodology. (L. Habib, Ed.) (4th ed.). Thousand Oaks, CA: SAGE Publications, Inc.

Wagner, C. N. (2016). Glued to the sofa: Exploring guilt and television binge-watching behaviors. Trinity University.

Walton-Pattison, E., Dombrowski, S., \& Presseau, J. (2018). 'Just one more episode': Frequency and theoretical correlates of television binge watching. Journal of Health Psychology, 23(1), 17-24. doi: 10.1177/1359105316643379

Wang, J., \& Calder, B. J. (2006). Media transportation and advertising. Journal of Consumer Research, 33(2), 151-162. doi: 10.1086/506296

West, K. (2014). Unsurprising: Netflix survey indicates people like to binge-watch TV. Cinema Blend, Television. Retrieved from http://www.cinemablend.com/television/UnsurprisingNetflix-Survey-Indicates-People-Like-Binge-Watch-TV-61045.html

Westcott, K., Lippstreu, S., \& Cutbill, D. (2017). Digital democracy survey. Demoitte Consulting LLP. New York, NY. https://doi.org/10.1002/ejoc.201200111 
Wheeler, K., \& Hackney, A. (2015). The relationships between television viewing behaviors attachment, loneliness, depression, and psychological well-being. Psychology. Georgia Southern University. 


\section{Tables and Figures}

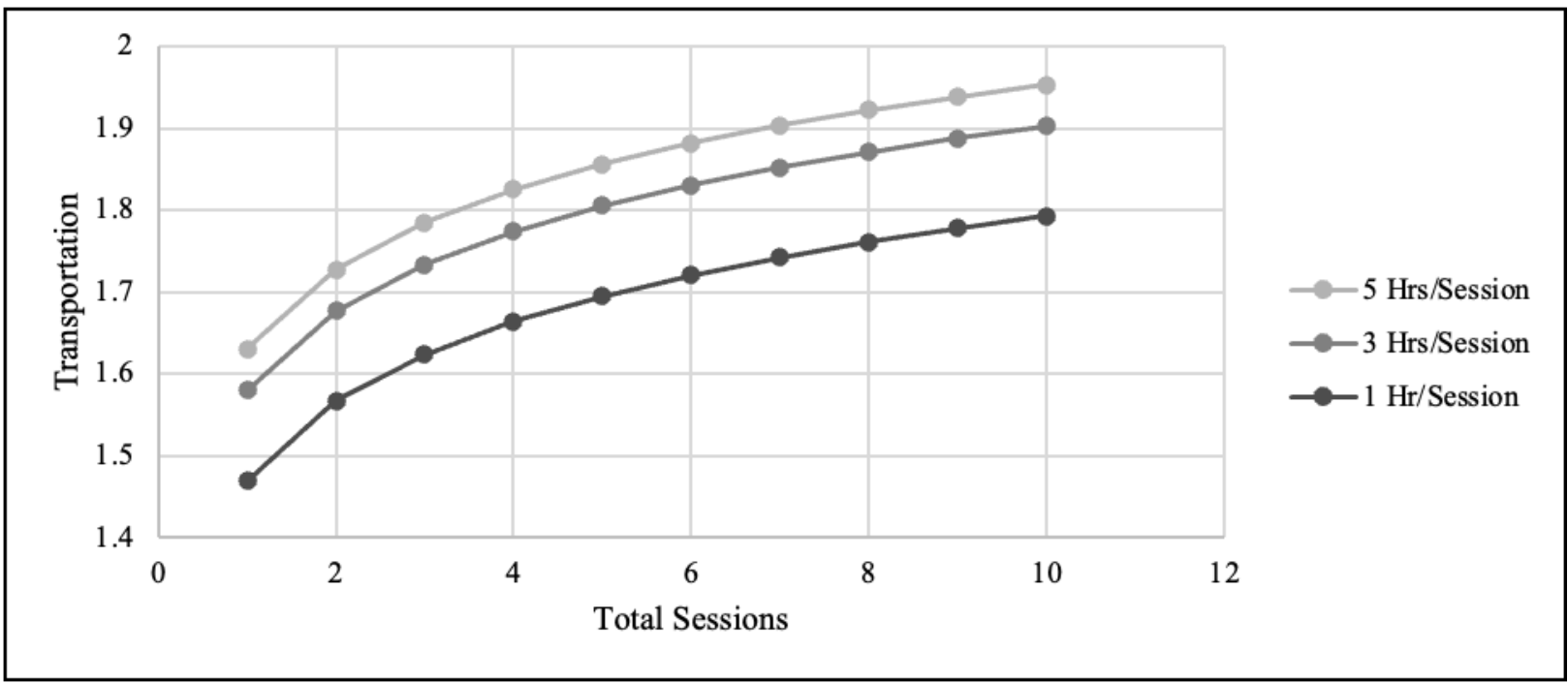

Figure 1. Transportation Based on Total Sessions and Length of Session (Upper/Lower Qs).

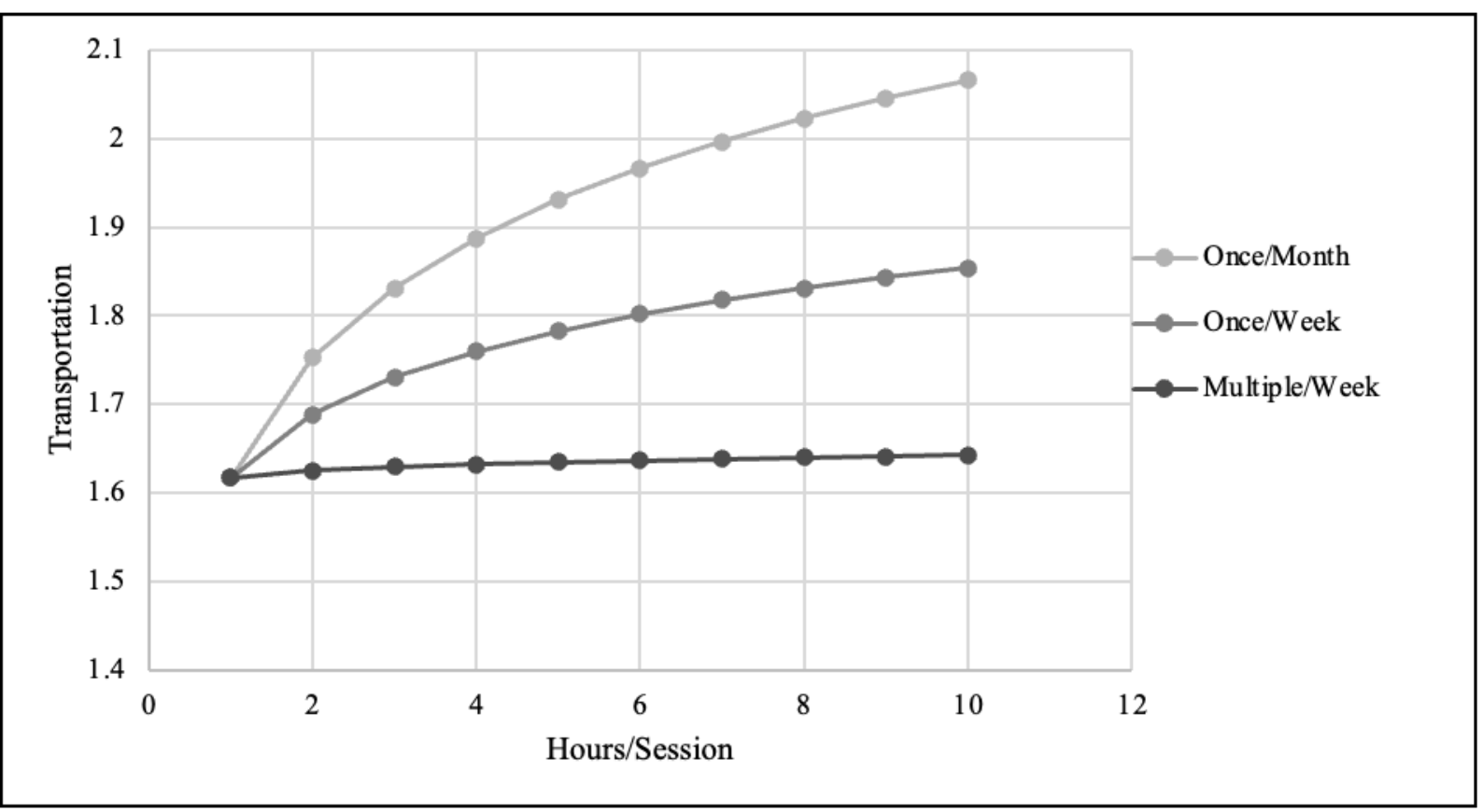

Figure 2. Average Session Length Effect on Transportation Separated by How Frequently Viewers Typically Binge-Watch (Quartiles; Average Weekly Session (2.86)) 
Table 1.

Effects of Binge-Watching and Viewing Habits on Transportation

\begin{tabular}{|c|c|c|c|c|c|c|c|c|c|}
\hline \multirow[b]{2}{*}{ Fixed Effect } & \multicolumn{3}{|c|}{ Model 1} & \multicolumn{3}{|c|}{ Model 2} & \multicolumn{3}{|c|}{ Model 3} \\
\hline & Coefficient & SE & $t$ Ratio & Coefficient & SE & $t$ Ratio & Coefficient & SE & $t$ Ratio \\
\hline \multicolumn{10}{|l|}{ Initial Transportation, $\pi_{0}$} \\
\hline Intercept, $\beta_{00}$ & $1.77 * * *$ & $(0.03)$ & 57.37 & $1.46^{* * *}$ & $(0.07)$ & 22.01 & $1.47 * * *$ & $(0.07)$ & 22.23 \\
\hline Familiarity, $\beta_{01}$ & --- & --- & --- & --- & --- & --- & $0.18^{*}$ & $(0.09)$ & -2.09 \\
\hline Binge Frequency, $\beta_{02}$ & --- & --- & --- & --- & --- & --- & $0.09 * *$ & $(0.03)$ & -2.89 \\
\hline \multicolumn{10}{|l|}{ Week, $\pi_{1}$} \\
\hline Intercept, $\beta_{10}$ & -0.04 & $(0.02)$ & -1.96 & -0.02 & $(0.02)$ & -0.96 & -0.02 & $(0.02)$ & -1.07 \\
\hline Familiarity, $\beta_{11}$ & --- & --- & --- & --- & --- & --- & -0.01 & $(0.03)$ & -0.37 \\
\hline Binge Frequency, $\beta_{12}$ & --- & --- & --- & --- & --- & --- & -0.001 & $(0.01)$ & -0.07 \\
\hline $\begin{array}{l}\text { Total Sessions }(\mathrm{Ln}), \pi_{2} \\
\text { Intercept, } \beta_{20}\end{array}$ & --- & --- & --- & $0.14 * * *$ & $(0.03)$ & 4.41 & $0.14 * * *$ & $(0.03)$ & 4.42 \\
\hline $\begin{array}{l}\text { Hours/Session }(\mathrm{Ln}), \pi_{3} \\
\text { Intercept, } \beta_{30}\end{array}$ & --- & --- & --- & $0.10^{\dagger}$ & $(0.05)$ & 1.88 & $0.103^{\dagger}$ & $(0.05)$ & 1.89 \\
\hline $\begin{array}{l}\text { Familiarity, } \beta_{31} \\
\text { Binge Frequency, } \beta_{32}\end{array}$ & -- & -- & $\begin{array}{ll}--- \\
---\end{array}$ & --- & --- & $\begin{array}{l}--- \\
---\end{array}$ & $\begin{array}{c}-0.12 \\
-0.046^{\dagger}\end{array}$ & $\begin{array}{l}(0.07) \\
(0.03)\end{array}$ & $\begin{array}{l}-1.62 \\
-1.77\end{array}$ \\
\hline Model Deviance & 585 & & & 543 & & & 525. & & \\
\hline
\end{tabular}

\begin{tabular}{|c|c|c|c|c|c|c|c|c|c|}
\hline Random Effect & $\begin{array}{c}\text { Variance } \\
\text { Component }\end{array}$ & $d f$ & $X^{2}$ & $\begin{array}{c}\text { Variance } \\
\text { Component }\end{array}$ & $d f$ & $X^{2}$ & $\begin{array}{c}\text { Variance } \\
\text { Component }\end{array}$ & $d f$ & $X^{2}$ \\
\hline \multicolumn{10}{|l|}{ Transportation } \\
\hline Intercept, $r_{0}$ & 0.13 & 179 & $534.92 * * *$ & 0.12 & 179 & $507.83 * * *$ & 0.11 & 177 & $475.17 * * *$ \\
\hline Week, $r_{l}$ & 0.02 & 179 & $260.81 * * *$ & 0.01 & 179 & $248.69 * * *$ & 0.01 & 177 & $239.53 * * *$ \\
\hline Level-1 effect, $e$ & 0.08 & & & 0.08 & & & 0.08 & & \\
\hline
\end{tabular}

Note. Observations $n=546$, Respondents $n=216(3 \mathrm{x})$. Familiarity and Binge Frequency are reported in natural log form.

${ }^{\dagger} p \leq .10 ; * p \leq .05 ; * * p \leq .01 ; * * * p \leq .001$. 


\section{Appendix A}

\begin{tabular}{lcc}
\multicolumn{3}{l}{ Television Show Options } \\
\hline \multicolumn{1}{c}{ Title } & Score* & IMDB Rating \\
\hline Breaking Bad & 25 & 9.5 \\
The Walking Dead & 17 & 8.7 \\
House of Cards & 16 & 9.1 \\
Orange is the New Black & 15 & 8.4 \\
Lost & 13 & 8.5 \\
Buffy the Vampire Slayer & 12 & 8.2 \\
Supernatural & 10 & 8.6 \\
American Horror Story & 10 & 8.3 \\
Dexter & 9 & 8.9 \\
Mad Men & 8 & 8.7 \\
\hline
\end{tabular}

Note. All available on Netflix.

* Score summed from selected binge-watching lists.

** Aggregated lists: (Bricker, 2015; Lawler, 2015; Pritchard, 2015; Ranker TV, 2015; Rotten

Tomatoes Staff, 2015; Skells, 2015; Smith, 2015) 